ARTIGO ORIGINAL

\title{
Análise do perfil fitoquímico e da atividade fotoprotetora do extrato aquoso de Plectranthus ornatus codd. (boldo chinês)
}

\author{
Analysis of the phytochemical profile and photoprotective activity of the aqueous extract of \\ Plectranthus ornatus codd. (chinese bold) \\ Mylena Medeiros Simões \\ Universidade Federal de Campina Grande, E-mail: mylenamedeirossimoes@gmail.com
}

Maria Francyherla Miguel da Silva Leite

Universidade Federal de Campina Grande, E-mail: francyherllaleiite@gmail.com

Fernanda Matias Cariri Marques

Universidade Federal de Campina Grande, E-mail: fernandacariri20@gmail.com

Bernadete Santos

Universidade Federal de Campina Grande, E-mail: bernadetes72@gmail.com

Maurício Maurício André Campos de Medeiros

Universidade Federal de Campina Grande, E-mail: mauricioandre64@ gmail.com

\author{
Abrahão Alves Oliveira Filho \\ Universidade Federal de Campina Grande, E-mail: abrahao.farm@gmail.com
}

\begin{abstract}
Resumo: A radiação ultravioleta faz parte do espectro eletromagnético transmitido pelo sol e inclui os comprimentos de onda ultravioleta (UV), que pode ser subdividida em U-VC, U-VB e U-VA. Esses raios UV podem ocasionar não só efeitos agudos como eritemas, queimaduras provocadas pelo sol e fotossensibilidade, mas também crônicos, como envelhecimento cutâneo e câncer de pele. Nesse sentido, a aplicação de produtos que funcionem como protetor solar é um meio eficiente para previnir e diminuir os efeitos das radiações UV. Assim, substâncias existentes nas plantas como taninos, alcaloides e flavonoides, podem ser utilizadas com o intuito de fornecer proteção à pele. Logo, esse trabalho teve como objetivo avaliar o perfil fitoquímico e o fator de proteção solar (FPS) do extrato aquoso de Plectranthus ornatus Codd., através do teste in vitro. Os dados foram submetidos à equação proposta por Mansur et al. (1986), para avaliar o FPS, realizando análises por espectrofotometria de varredura na região UV-B. Além disso, foi realizada a análise fitoquímica com base em reações químicas que resultaram em alteração da coloração e/ou precipitação que são específicos, através da metodologia de Matos (1997), na qual indicou a presença dos metabólitos secundários alcaloides e taninos. Avaliando os resultados alcançados, nota-se que as concentrações de $500 \mu \mathrm{g} . \mathrm{mL}-1$ e $1000 \mu \mathrm{g} . \mathrm{mL}-1$, apresentaram potencial fotoprotetor, com FPS 6,99 e 14,07, respectivamente, sugerindo uma possível utilização como protetor solar em fitocosméticos.
\end{abstract}

Palavras-chave: Fitoterapia. Metabólitos Secundários. Fotoproteção.

Abstract: Ultraviolet radiation is part of the electromagnetic spectrum transmitted by the sun and includes ultraviolet (UV) wavelengths, which can be subdivided into U-VC, U-VB and U-VA. These UV rays can cause not only acute effects such as erythema, sunburn and photosensitivity, but also chronic ones, such as skin aging and skin cancer. In this sense, the application of products that work as a sunscreen is an efficient way to prevent and reduce the effects of UV radiation. Thus, substances existing in plants such as tannins, alkaloids and flavonoids, can be used in order to provide protection to the skin. Therefore, this work aimed to evaluate the phytochemical profile and the sun protection factor (SPF) of the aqueous extract of Plectranthus ornatus Codd., Through the in vitro test. The data were submitted to the equation proposed by Mansur et al. (1986), to evaluate the SPF, performing analyzes by scanning spectrophotometry in the UV-B region. In addition, a phytochemical analysis was carried out based on chemical reactions that resulted in changes in color and/or precipitation that are specific, through the methodology of Matos (1997), in which he indicated the presence of secondary alkaloids and tannins. Evaluating the results achieved, it is noted that the concentrations of $500 \mu \mathrm{g} . \mathrm{mL}-1$ and $1000 \mu \mathrm{g} . \mathrm{mL}-1$, showed photoprotective potential, with SPF 6.99 and 14.07, respectively, suggesting a possible use as a sunscreen in phytocosmetics.

Key words: Phytotherapy. Secondary Metabolites. Photoprotection.

Recebido em: 15/01/2020

Aprovado em: 25/02/2020

Rev. Bra. Edu. Saúde, v. 10, n.1, p. 156-161, jan-mar, 2020. 


\section{INTRODUÇÃO}

A radiação ultravioleta faz parte do espectro eletromagnético que o sol transmite, além de incluir os comprimentos de onda ultravioleta (UV) entre 100-400 $\mathrm{nm}$ e ser subdividida em U-VC (100-280 nm), U-VB (280-320 nm) e U-VA (320-400 nm) (GONÇALVES et al., 2018). Com isso, quanto menor o comprimento de onda, maior será a energia da radiação solar, por isso a UV, como apresenta um ínfimo, é a que possui energia mais elevada, sendo predisposta a induzir reações fotoquímicas (DAHER, 2014).

Ainda, os raios UV excedentes, podem ocasionar não só efeitos agudos como eritemas, queimaduras provocadas pelo sol e fotossensibilidade, mas também crônicos, tais como envelhecimento cutâneo e câncer de pele (CORREA, 2012). Igualmente, moléculas como o DNA, que é uma das principais na absorção de radiações UV, caso sofra mutações, estas podem se tornar malignas (BALOGH et al., 2011).

Da mesma maneira, a redução da camada de ozônio, consequentemente, provoca uma expansão da radiação U-VB na superfície terrestre (LIU et al., 2012). Esses raios possuem competência para penetrar na epiderme completamente e relativamente na derme, levando ao espessamento da camada de queratina, além de provocar o bronzeamento indireto, que é responsável pelas queimaduras e câncer no tecido epitelial (SCHNEIDER, 2000; TOFETTI, 2006). Esse tipo de câncer pode ser definido como um tumor que atinge a pele, além de ser o mais presente no Brasil e no mundo (MINISTÉRIO DA SAÚDE, 2020).

Adicionalmente, o câncer cutâneo acontece no momento em que as células se proliferam descontroladamente, sendo do tipo melanoma, quando surge nas células que produzem a melanina (responsável pela coloração), mais comum em adultos de cor clara, e do tipo não melanoma que é o mais recorrente no Brasil, com um percentual de $30 \%$ dos casos de abscessos malignos que foram registrados no País (MINISTÉRIO DA SAÚDE, 2020). Assim sendo, de acordo com o Instituto Nacional de Câncer (2020), os trabalhadores que se expõe regularmente ao sol possuem chances maiores de adquirirem o câncer não melanoma.

Nesse sentido, a aplicação de produtos que funcionem como protetor solar é um meio eficiente para prevenção, como também diminuição dos efeitos agudos e crônicos dos raios UV (DAMIANI et al., 2006). Sendo o fator de proteção solar um dado numérico presente nos rótulos dos protetores solares, no qual relaciona a parcela mínima de radiação UV precisa para fornecer uma queimadura na pele que está protegida pelo filtro e a necessária para causar o mesmo efeito em uma pele sem proteção (DIFFEY, 2001). Logo, as substâncias existentes nas plantas que podem ser utilizadas com o intuito de fornecer uma proteção à pele mais abrangente em sua fórmula, são os antioxidantes como as vitaminas $\mathrm{C}$ e $\mathrm{E}$, taninos, alcaloides e os flavonoides (SIMÕES et al., 2004; VIOLANTE et al., 2009).

Nesse seguimento, a planta Plectranthus ornatus Codd. é pertencente a família Lamiaceae e conhecida popularmente como boldo chinês, boldo gambá, boldo miúdo ou boldo rasteiro (MAURO et al., 2008) Além de ter sua origem no continente Africano e sido introduzida no Americano pelos portugueses (LUKHOBA et al., 2006). Segundo Costa e Nascimento (2003), no Nordeste brasileiro é frequentemente empregada para fins medicinais como analgésico, para estimular o apetite, também nos casos de doenças no fígado e estômago.

Eventualmente, é imprescindível a busca por espécies vegetais com propriedades químicas que diminuam os danos causados pela radiação, sendo necessário averiguar os metabólitos secundários presispostos à proteção que podem estar presentes no extrato. Assim, o Plectranthus ornatus apresenta em suas partes aéreas três diterpenóides, semelhantes à forskolina (RIJO et al., 2002). Da mesma forma que, de acordo com Mesquita (2016), foi isolado em suas folhas o ácido cafeico, além dos flavonoides circimaritina e pedalatina. Desse modo, o trabalho buscou avaliar o perfil fitoquímico e a atividade fotoprotetora do extrato aquoso de Plectranthus ornatus Codd.

\section{MATERIAL E MÉTODOS}

\section{Extrato Vegetal}

Para realização do estudo in vitro da espécie Plectranthus ornatus Codd., foi feita a coleta de suas partes aéreas, que foram identificadas pela Prof $^{a}$. Dr ${ }^{a}$. Maria de Fátima de Araújo Lucena. Além disso, uma exsicata da planta, com numeração 7142, encontra-se depositada no Herbário CSTR (Centro de Saúde e Tecnologia Rural), da Universidade Federal de Campina Grande, Campus de Patos- PB. Para produção do extrato aquoso da amostra vegetal, utilizou-se a metodologia descrita por Ferris e Zheng (1999), com modificações.

\section{Perfil fitoquímico de Plectranthus ornatus Codd.}

Analisou-se a presença dos metabólitos secundários: alcaloides, esteroides e triterpenoides, flavonoides, saponina espumídica e taninos. Para isso, o extrato aquoso de Plectranthus ornatus foi submetido à análise fitoquímica com base em reações químicas que resultaram em alteração da coloração e/ou precipitação que são específicos, através da metodologia de Matos (1997), com modificações.

\section{Avaliação do Fator de Proteção Solar do extrato aquoso de Plectranthus ornatus Codd.}

A espectrofotometria de absorção do extrato aquoso de Plectranthus ornatus aconteceu no espectro da radiação ultravioleta como proposto por Mansur et al.(1986), assim realizou-se varreduras de 290 a 320nm (em intervalos de $5 \mathrm{~nm}$ ) com duração de 5 minutos, sendo que ao término desse tempo foi efetuado as mensurações das absorbâncias. Para a leitura utilizou- 
se o espectrofotômetro digital (Biospectro®) com cubeta de quartzo de $1 \mathrm{~cm}$.

Após a mensuração das absorbâncias, os dados foram submetidos à equação de Mansur et al. (1986) para aferir o FPS in vitro. Esse método coloca em lista o efeito eritematogênico e a intensidade da radiação (EE X I) que foram medidos por Sayre et al. (1979), esses são demostrados na Tabela 1, logo abaixo:

Tabela 1. Relação efeito eritemogênico (EE) versus intensidade da radiação (I) conforme o comprimento de onda $(\lambda)$.

\begin{tabular}{ll}
\hline$\lambda / \mathbf{n m}$ & EE x I \\
\hline 290 & 0,0150 \\
295 & 0,0817 \\
300 & 0,2874 \\
305 & 0,3278 \\
310 & 0,1864 \\
315 & 0,0839 \\
320 & 0,0180 \\
\hline
\end{tabular}

Fonte: SAYRE et al., 1979.

Sendo que a fórmula de Mansur et al. (1986) é também composta pela leitura espectrofotométrica da absorbância da solução e fator de correção (=10). Essa equação pode ser observada, a seguir:

FPS espectrofotométrico $\underset{290}{320} \mathrm{FC} . \Sigma \mathrm{EE}(\lambda) . \mathrm{I}(\lambda)$. Abs $(\lambda)$

$\mathrm{Na}$ qual: FPS = fator de proteção solar; $\mathrm{FC}=$ fator de correção, calculado de acordo com dois filtros solares de FPS conhecidos e testados em seres humanos de tal forma que um creme contendo $8 \%$ de homossalato resultasse no $\operatorname{FPS} 4 ; \operatorname{EE}(\lambda)=$ efeito eritemogênico da radiação de comprimento de onda; I $(\lambda)=$ a intensidade da luz solar no comprimento de onda e Abs $(\lambda)=$ a absorbância da formulação no comprimento de onda.

\section{RESULTADOS E DISCUSSÃO}

Segundo Rosa et al. (2016), pesquisas fitoquímicas são extremamente úteis, pois indicam a existência dos vários compostos com origem no metabolismo secundário das plantas, que podem provocar diversos efeitos nos organismos expostos aos mesmos.

Desse modo, a análise fitoquímica do extrato aquoso das folhas de Plectranthus ornatus, exposta na tabela 2, indica a presença dos metabólitos secundários alcaloides e taninos.

Tabela 2. Análise fitoquímica de Plectranthus ornatus Codd.

Alcaloides

Esteroides e triterpenoides

Flavonoides

Saponina espumídica

Taninos

Legenda: (+) presença; (-) ausência.

É possível que os alcaloides apresentem entre suas funções a defesa contra os raios ultravioleta, em virtude de, em sua maior parte, serem compostos com núcleos aromáticos que contém alto poder de absorção desses raios (HENRIQUES et al., 2000). Do mesmo modo que a presença de taninos manifesta potencial para absorver a radiação UV (SANTANA et al. 2001).

$\mathrm{Na}$ pesquisa de Alves et al. (2018), testes fitoquímicos no extrato obtido através da maceração em etanol (96\%) das folhas da espécie Plectranthus ornatus Codd., revelou a presença de fenóis (taninos condensados).
Porém, apesar de terem sido obtidos significativos teores de compostos fenólicos no extrato aquoso de Plectranthus ornatus, trabalhos como o de Nascimento (2017), relatam a presença de compostos como os triterpenos obtidos dos extratos de gasolina e diclorometano dessa espécie. A ausência desses metabólicos secundários nesse estudo pode ser explicada por Vizzoto (2009), quando relata que a água destilada não é considerada um bom extrator.

Em relação ao fator de proteção solar, Daher (2014), relata que substâncias provenientes das plantas têm sido apontadas ultimamente como um recurso para 
serem utilizadas nas formulações de fotoprotetores, tendo em vista sua absorção no espectro ultravioleta, bem como caraterísticas antioxidantes.

Além do mais, o uso de protetores solares é o mais essencial tratamento cosmético contra os danos da radiação UV, diminuindo a quantidade de doenças causadas pela exposição excessiva e sendo utilizados como medida preventiva para o envelhecimento cutâneo (WANG et al., 2010; BALOGH et al., 2011).
Do mesmo modo que a proteção contra os raios solares compreende a atitude mais eficiente para prevenir o câncer de pele (COSTA, 2012).

Sendo assim, os resultados da atividade fotoprotetora do extrato aquoso de Plectranthus ornatus Codd., efetuadas no espectro da radiação UVB (290 a $320 \mathrm{~nm})$, podem ser observados na tabela 3.

Tabela 3. Valores de FPS do extrato de Plectranthus ornatus em diferentes concentrações.

Fonte: Dados da pesquisa, 2020.

\begin{tabular}{|c|c|c|c|c|}
\hline Concentrações ( $\mu$ g.mL-1) & $50 \mu \mathrm{g} / \mathrm{m}$ & $100 \mu \mathrm{g} / \mathrm{mL}$ & $500 \mu \mathrm{g} / \mathrm{mL}$ & $1000 \mu \mathrm{g} / \mathrm{mL}$ \\
\hline FPS & 0,42 & 4,37 & 6,99 & 14,07 \\
\hline
\end{tabular}

Avaliando os resultados alcançados, nota-se que as concentrações de $500 \mu \mathrm{g} . \mathrm{mL}-1$ e $1000 \mu \mathrm{g} . \mathrm{mL}-1$, apresentaram potencial fotoprotetor, com FPS 6,99 e 14,07, respectivamente, demonstrando valores promissores para o estudo.

Tendo em vista a resolução - RDC N 30 , de $1^{\circ}$ de junho de 2012, da Agência Nacional de Vigilância Sanitária (ANVISA), que aprova o regulamento técnico MERCOSUL a respeito dos protetores solares em cosméticos e dá outras providências, o fator mínimo de proteção solar estabelecido é 6 (BRASIL, 2012).

Diante disso, os resultados desse estudo in vitro indicam que o extrato aquoso de Plectranthus ornatus Codd. nas concentrações de $500 \mu$ g.mL-1 e $1000 \mu \mathrm{g} . \mathrm{mL}-1$, poderia ser utilizado como protetor solar em fitocosméticos.

Conforme a pesquisa de Rosa et al. (2008), a análise espectral do extrato aquoso a partir de uma concentração de $10 \%$ (massa de planta triturada/volume de água) demonstrou a promoção de fotoproteção nas regiões, tanto UV-A, quanto UV-B, resultando fatores de proteção solar em torno de 8 para Achillea Millefolium, 6 para Sonchus oleraceus, 5 para Porophylum ruderale (Jacq.) Cass. e Brassica oleracea var. capitata, 2 para Plectrantus barbatus e 1 para Cyperus rotundus.

Segundo o trabalho de Simão et al. (2019), o extrato etanólico de Cnidoscolus quercifolius Pohl (favela, ou favela- de- cachorro) nas concentrações de 500 e $1000 \mu \mathrm{g} . \mathrm{mL}-1$, apresentou FPS de 6,48 e 14,30, respectivamente.

No estudo de Vieira e Orlanda (2018), foi encontrado no extrato etanólico de Ocimum gratissimum L. (alfavaca, Lamiaceae) um valor de FPS $\geq 6,0$ nas concentrações de 0,01 a $0,09 \mu \mathrm{g} \cdot \mathrm{mL}^{-1}$, determinando sua possível utilização como protetor solar de origem natural.

\section{CONCLUSÃO}

Nesse sentido, os resultados obtidos nessa pesquisa expressam o potencial fotoprotetor, bem como a análise fitoquímica do extrato aquoso de
Plectranthus ornatus Codd. in vitro, sugerindo uma possível utilização para fins terapêuticos em fitocosmésticos. Entretando, mais estudos são necessários, como in vivo, para produção de um protetor solar.

\section{REFERÊNCIAS}

ALVES, F. A.R. et al. Chemical composition, antioxidant and antifungal activities of essential oils and extracts from Plectranthus spp. against dermatophytes fungi. Revista Brasileira de Saúde e Produção Animal, v. 19, n. 1, p. 105-115, 2018.

BALOGH, T. S. et al. Proteção à radiação ultravioleta: recursos disponíveis na atualidade em fotoproteção. Anais Brasileiros de Dermatologia, v. 86, n. 4, p. 732-742, 2011.

BRASIL, 2012. Resolução RDC no 30 , de $1^{\circ}$ de junho de 2012. Aprova o regulamento técnico "Mercosul sobre Protetores Solares em Cosméticos e dá outras providências." Diário Oficial da República Federativa do Brasil, Brasília, DF, 4 de junho de 2012.

CORRÊA, M. A. Cosmetologia: Ciência e Técnica. $1^{a}$ edição. São Paulo: Livraria e Editora Medfarma, 2012.

COSTA, C. S. Epidemiologia do câncer de pele no Brasil e evidências sobre sua prevenção. Revista Diagnóstico e Tratamento, São Paulo, v. 4, n. 17, p. 206-208, 2012.

COSTA, M.C.C.D.; NASCIMENTO, S.C. Atividade Citotóxica de Plectranthus barbatus Andr. (Lamiaceae). Acta Farmacêutica Bonaerense. v.22, n. 2, p.155158, 2003.

DAHER, C.C. Desenvolvimento de emulsões o/a contendo extrato glicólico de açai e avaliação da atividade fotoprotetora, 2014. (Dissertação de 
mestrado) - Universidade Federal do Rio Grande do Norte (UFRN), Natal - RN, 2014.

DAMIANI, E. et al. Changes in ultraviolet absorbance and hence in protective efficacy against lipid peroxidation of organic sunscreens after UVA irradiation. Journal of Photochemistry and Photobiology B: biology, v. 82, n. 3, p. 204-213, 2006.

DIFFEY, B. Sunscreen Isn't enough. Journal of Photochemistry and photobiology B: biology, v. 64, n. 2-3, p. 105-108, 2001.

FERRIS, H.; ZHENG, L. Plant sources of chinese herbal remedies: effects on Pratylenchus vulnus and Meloidogyne javanica. Journal of nematology, Lawrence, v. 31, n. 3, p. 241-263, 1999.

GONÇALVES, M.C. et al. Estudos preliminares da citoxicidade e propriedades fotoprotetoras de derivados de Benzofenonas e Lactonas. Revista Virtual de Química, v. 10, n. 3, p. 600-608, 2018.

HENRIQUES, A.T.; KERBER, V.A.; MORENO, P.R.H. Alcalóides: generalidades e aspetos básicos. In: Farmacognosia: da planta ao medicamento. 2. ed. UFRGS/UFSC: Porto Alegre/Florianópolis, p. 641$642,2000$.

INCA. Câncer de pele não melanona: o que aumenta o risco. Instituto nacional de câncer (INCA), 2020. Disponível em: https://www.inca.gov.br/tiposde-cancer/cancer-de-pele-nao-melanoma. Acesso em: 17 de fevereiro de 2020.

LIU, S. et al. Protein indicators for HaCaT cell damage induced by UVB irradiation. Journal of Photochemistry and Photobiology B: Biology, v. 114, p. 94-101, 2012.

LONNI, A. A.S.G. et al. Fluorescência de raios X por dispersão de energia aplicada no controle de qualidade de protetor solar. Latin American Journal of Farmacy, v. 27, n.5, p. 661-667, 2018.

LUKHOBA, C.W.; SIMMONDS, M.S.J; PATON, A.J. Plectranthus: A review of ethnobotanical uses. Journal of ethnopharmacology, v. 103, n. 1, p. 1-24, 2006.

MANSUR, J. S., BREDER, M. V. R., MANSUR, M. C. A., AZULAY, R. D. Correlação entre a determinação do fator de proteção solar em seres humanos e por espectrofotometria. Anais Brasileiros de Dermatologia, v.61, p.121-124, 1986.

MATOS, F. J. A. Introdução à fitoquímica experimental. $2^{\circ}$ edição. Fortaleza: Edições UFC, 1997.

MAURO, C. et al. Estudo anatômico comparado de órgãos vegetativos de boldo miúdo, Plectranthus ornatus Codd. e malvariço, Plectranthus amboinicus (Lour.) Spreng. - Lamiaceae. Revista Brasileira de Farmacognosia, João Pessoa, v.18, n.4. p.608-613, 2008.

MESQUITA, L. S. F. Prospecção química do extrato etanólico das folhas de Plectranthus ornatus Codd. 2016. 193 f. Dissertação de Mestrado (Química Orgânica) - Programa de Pós-Graduação em Química, Universidade Federal do Ceará, Fortaleza, 2016.

MINISTÉRIO DA SAÚDE. O que é câncer de pele. 2020. Disponível em: https://www.saude.gov.br/saude-dea-z/cancer-de-pele. Acesso em: 08 de abril de 2020.

MINISTÉRIO DA SAÚDE. Tipos de câncer de pele. 2020. Disponível em: https://www.saude.gov.br/saude-dea-z/cancer-de-pele. Acesso em: 18 de fevereiro de 2020.

NASCIMENTO, F.R. et al. Atividade antibiótica de Plectranthus ornatus Codd., uma planta medicinal tradicional. Anais da Academia Brasileira de Ciências , v. 89, n. 3, p. 2461-2469, 2017.

RIJO, P. et al. Neoclerodane and Labdane Diterpenoids from Plectranthus o rnatus. Journal of natural products, v. 65, n. 10, p. 1387-1390, 2002.

ROSA, M.B. et al. Estudo espectrofotométrico da atividade foto-protetora de extratos aquosos de Achillea millefolium, Brassica oleracea Var. Capitata, Cyperus rotundus, Plectranthus barbatus, Porophyllum ruderale (Jacq.). Revista Eletrônica de Farmácia, v. 5, n. 1, 2008.

ROSA, R.C.A. et al. Triagem fitoquímica dos extratos aquosos de Bauhinia candicans, Foeniculum vulgare, Mentha pulegium e Morus nigra. Conexão Ciência (Online), v. 11, n. 1, p. 44-51, 2016.

SANTANA, J. L. et al. Evaluación de la actividad antimicrobiana, fotoprotectora, antielastasa y antioxidante de polifenois de origen natural, empleados wen formulaciones cosméticas. In: XV Congresso Latino-americano e Ibérico de Químicos Cosméticos. Buenos Aires, Argentina, p. 332-343, 2001.

SAYRE, R.M. et al. A comparison of in vivo and in vitro testing of sunscreening formulas. Photochemistry and Photobiology, v. 29, n. 3, p. 559-566, 1979.

SCHNEIDER, L. V Curso Extensivo de Cosmetologia. Módulo I-Estrutura da Pele e seus Anexos. Porto Alegre, p. 2-13, 2000.

SIMÃO, K.L.A. et al., Avaliação do potencial fotoprotetor do extrato etanólico das folhas de cnidoscolus quercifolius pohl. Revista International 
Journal of Development Research, Vol. 09, Issue, 09, pp. 29883-29886, September, 2019.

SIMÕES, C.O et al. Farmacognosia da Planta ao Medicamento. $5^{\text {a }}$ edição. Porto Alegre/Florianópolis: Editora UFRGS/ Editora UFSC, 2004.

TOFETTI, M.H.F.C.; DE OLIVEIRA, V.R. A importância do uso do filtro solar na prevenção do fotoenvelhecimento e do câncer de pele. INVESTIGAÇÃO, v. 6, n. 1, 2006.

VIEIRA, C. B. S.; ORLANDA, J. F. F. Atividade antioxidante e fotoprotetora do extrato etanólico de Ocimum gratissimum L. (alfavaca, Lamiaceae). Revista Cubana de Plantas Medicinales, v.23, n.3, 2018.
VIOLANTE, I.M.P et al. Avaliação in vitro da atividade fotoprotetora de extratos vegetais do cerrado de Mato Grosso. Revista Brasileira de Farmacognosia, v.19, n.2A, p. 452-457, 2009.

VIZZOTTO, M.; PEREIRA, M.C. Metodologia científica: otimização do processo de extração de compostos fenólicos antioxidantes de mirtilo (Vaccinium ashei Reade). Embrapa Clima Temperado, 2009.

WANG, S. Q., BALAGULA, Y., OSTERWALDER, U. Photoprotection: a review of the current and future technologies. Dermatology and Therapy, v. 23, n.1, p. $31-47,2010$. 